\title{
PET FIBRE REINFORCED COCONUT SHELL CONCRETE (PFRCSC)
}

\author{
Bharati Raj ${ }^{1}$, Beegumafsana $\mathrm{A}^{2}$, Jasmine Thajudeen ${ }^{2}$, Rahna $\mathrm{L}^{2}$, Shifana $\mathrm{S}^{2}$, Swathi MS ${ }^{2}$ \\ ${ }^{1}$ Assistant Professor, Dept. of Civil Engineering, Rajadhani Institute of Engineering \& Technology (RIET), Nagaroor, \\ Alamcode, Attingal, Thiruvananthapuram, Kerala, India \\ bharatiraj@rietedu.in \\ ${ }^{2}$ B.Tech student, Dept. of Civil Engineering, Rajadhani Institute of Engineering \& Technology (RIET), Nagaroor, \\ Alamcode, Attingal, Thiruvananthapuram, Kerala, India
}

bharatiraj83@gmail.com

\begin{abstract}
Aggregates generally occupy $60 \%$ to $75 \%$ of the concrete volume and strongly influence the fresh and hardened properties and economy of concrete. The continued extraction of aggregates from nature has caused its depletion at an alarming rate. The worldwide depletion of natural resources and the simultaneous accumulation of waste materials call for the need for sustainable development in the construction industry. Hence, recent researches have been focussed on the use of locally available waste materials such as coconut shell, plastic, etc., in concrete to replace the mineral aggregates. This study deals with the strength characteristics of PET fibre reinforced coconut shell concrete (PFRCSC). Earlier studies have shown that when coconut shell was used in concrete to replace the coarse aggregates, compressive strength was decreased considerably. But, this reduction in strength was significantly low for $10 \%$ coarse aggregate replacement. Also, the inclusion of polythene fibres made from waste plastic bottles was noted to improve the strength characteristics of concrete. Hence, an attempt has been made to combine the positive characteristics of both coconut shell concrete (CSC) and PET Concrete. M30 normal concrete and CSC concrete with $10 \%$ coarse aggregate of normal concrete replaced by coconut shell has been taken as thecontrol mixes. PET fibres made from waste plastic bottles were added at volume fractions of 0, 0.5, 1, 1.5 and 2\%. The mechanical properties such as density, compressive strength, tensile strengthand flexural strength were determined and compared with the control mixes. The experimental investigations were carried out on a total of 180 specimens which includes cubes, cylinders and prisms. The results indicate that PFRCSC is a sustainable, eco-friendly and economical concrete with better engineering properties and strength characteristics in comparison with normal concrete and coconut shell concrete.
\end{abstract}

Key Words:Coconut, Fibres, Plastic, Polythene, And Sustainable

$* * *$

\section{INTRODUCTION}

Sustainability in building developments is a vast and complex subject that must be considered from the very earliest stages as the potential environmental impacts are very significant. In the present day construction industry, the rising cost of building construction materials is becoming a factor of great concern. The prices of building materials are rising day by day. Concrete has always been considered as the premier building material and aggregates form the main ingredient of concrete. The continued extraction of aggregates from nature has caused its depletion at an alarming rate. The worldwide depletion of natural resources and the simultaneous accumulation of waste materials have called for the need for sustainable development in the construction industry. This mainly involves the use of locally available materials as replacement of the natural aggregates, both coarse and fine aggregates. Hence, recent researches have been focussed on the use of locally available waste materials such as coconut shell, plastic, etc., in concrete to replace the mineral aggregates.

Coconut shells areone of the agricultural waste products abundantly available from local coconut fields in Kerala and accounts for around $45 \%$ of the production in India. In many countries, coconut shell is subjected to open burning which contributes significantly to $\mathrm{CO}_{2}$ and methane emissions. The disposal of coconut shell posesvarious environmental issues as it is not easily degradable and it is an agricultural waste. In India, coconut shell when used as an agricultural waste requires huge dumping yards. The dumping of coconut shell also causes breeding place for mosquitoes.If this material can be utilised to replace the coarse aggregates in concrete, then it should be a boon to the civil engineering society.Various researchers [1-5] have investigated the use of coconut shells and their derivatives in civil engineering construction. This will not only reduce the weight of the resulting concrete, but also provides an efficient solution to the disposal of coconut shells.

Plastic waste is yet another crucial issue posing various environmental hazards. The amounts of plastics, especially the plastic bottles consumed annually have been increasing steadily. There are several factors that contribute to the rapidly growth of plastics consumption such as low density, fabrication capabilities, long life, lightweight, and low cost of production.The problem gets further complicated since plastic waste is not degradable and may cause environmental disturbance. Treatment method through incineration will provide toxic gas like dioxin that could be dangerous to human health. The main disadvantage of PET (Polyethylene Terephthalate) bottles is the shear amount of 
time they take to decompose, an average plastic bottle takes 500 years. The decomposition can be affected by various factors, such as climate and acids in the landfill.Of the mass numbers of plastic bottles consumed throughout the world, most of them are not recycled because only certain types of plastic bottles can be recycled by certain municipalities. They either end up lying stagnant in landfills, leaching dangerous chemicals into the ground, or they infiltrate our streets as litter. They are found on sidewalks, in parks, front yards and rivers, and even if you chop them into tiny pieces they still take more than a human lifetime to decompose.

A possible application of disposing these hazardous PET bottles is to chop them into fibres and use Polyethylene Terephthalate (PET)fibres obtained from waste plastic bottles as short fibre reinforcement in structural concrete.It can improve its tensile strength as concrete is good in compressive strength but lack tensile strength. The reduced strength is mainly due to presence of micro and macro cracks due to shrinkage of concrete. PET comes in the category of low modulus synthetic fibres along with fibres of polyethylene, nylon, polyester which are effective in controlling shrinkage cracking but is not so effective in increasing tensile strength. Also, PET bottles are being experimented to act as non-load bearing and partition walls in many parts of world. Previous researches $[6,8,9,11,14]$ revealed that PET waste fibre in concrete has significant role in terms of bonding and strength. Increasing the PET waste increases the size of porosity and interfacial transition zone in concrete matrix and resulted in reduction in strength of concrete.

\section{SIGNIFICANCE OF THE WORK}

Though there are various waste materials that form a part of garbage, non-biodegradablewastes like plastic are more visible than other trash. This is especially true in case of PET (Polyethylene Terephthalate) bottles. These bottles not only result in waste of expensive material but also increase plastic waste which can cause environment pollution in the form of their disposal. Today, PET bottle wastes are seen everywhere: on the road, in garbage bins, railways tracks, play grounds, etc. This calls for a need for using these waste materials in a useful manner.

Studies have revealed that the addition of fibres improves the engineering properties of concrete such as ductility, post crack resistance, energy absorption capacity, etc. The inclusion of fibres also imparts better flexural strength, cracking resistance and toughness characteristics to the concrete. Research has been carried out on the properties of concrete including polythene fibres obtained from plastic bottles and it has been noted that the compressive strength was improved when the polythene fibre volume fraction was increased from 0 to $2 \%$. Hence, the inclusion of such fibres would prove to be beneficial to the concrete properties.

This creates a possibility of including PETfibres to the Coconut Shell Concrete (CSC) to improve the strength characteristics of concrete. Research available on coconut shell concrete and polythene fibre concrete has been restricted to the studies on mechanical properties such as compressive strength, tensile strength, density, water absorption and flexural strength. The possibility of inclusion ofpolythene fibresto coconut shell concrete has not been explored so far.

Thispaper aims at analysing the mechanical properties of Polythene Fibre Reinforced Coconut Shell Concrete(PFRCSC).

The major objectives are

- To study the characteristics of coconut shell concrete with $10 \%$ coconut shell as partial replacement of coarse aggregates.

- To analyse the possibility of inclusion of polythenefibres to coconut shell concrete at volume fractions of $0,0.5,1,1.5$, and $2 \%$.

- To evaluate the engineering properties such as density,compressive strength, tensile strength and flexural strength of Polythene Fibre Reinforced Coconut Shell Concrete

\section{EXPERIMENTAL PROGRAMME}

\subsection{Materials and Mix Proportions}

Ordinary Portland cement of43 Grade having specific gravity 3.15 and normal consistency of $38 \%$ and conforming to IS:12269-1987(Reaffirmed 2004) [15]was used. M sand passing through $4.75 \mathrm{~mm}$ IS sieve conforming to grading Zone IIof IS 383-1970 (Reaffirmed 2002) [16] was used as fine aggregate. Crushed stone having effective size of 10.2mm conforming to IS: $2386-1997[17,18]$ and IS: $383-$ 1970 (Reaffirmed 2002) [16]was used as coarse aggregate.

The mix designs were carried out for obtaining 28day concrete compressive strengths of $30 \mathrm{MPa}$. Locally available coconut shells were crushed and sieved to get coarse particles with effective size of 15 to $20 \mathrm{~mm}$ and bulk density $1.69 \mathrm{~g} / \mathrm{cc}$ as shown in Fig.1. The natural coarse aggregates were replaced at a volume fraction of $10 \%$ with coconut shell and polythene fibres obtained from polythene bottles were added at volume fractions of $0,0.5,1,1.5$ and $2 \%$.

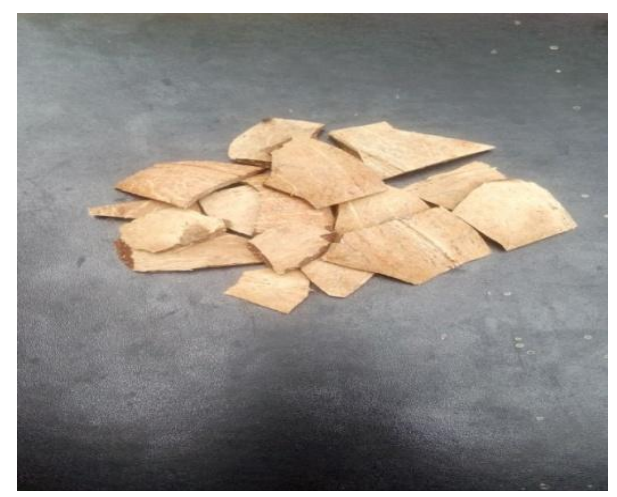

Fig 1 Coconut shell

The coconut shell content was restricted to $10 \%$ by volume of coarse aggregates as the optimum value of coconut shell content for desirable compressive strength for the mix was found to be $10 \%$ from past literature $[7,12,13]$. Polyethylene 
terephthalate (PET) fibres having an aspect ratio of 88 were cut from waste PET bottles (Fig.2). The length of the fibres was $40 \mathrm{~mm}$.Potable water available in the laboratory, which satisfies drinking standards, was used for the concrete mixing and its subsequent curing. The mix proportion used is as given in Table 1.

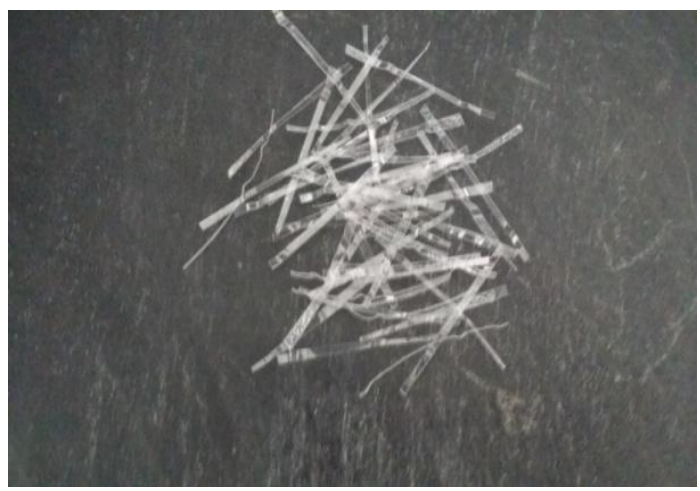

Fig 2 PET Fibres

Table 1 Mix proportions

\begin{tabular}{|l|l|l|l|l|}
\hline $\begin{array}{l}\text { Cement } \\
\left(\mathrm{kg} / \mathrm{m}^{3}\right)\end{array}$ & $\begin{array}{l}\text { Coarse } \\
\text { Aggregate } \\
\left(\mathrm{kg} / \mathrm{m}^{3}\right)\end{array}$ & $\begin{array}{l}\text { Fine } \\
\text { Aggregate } \\
\left(\mathrm{kg} / \mathrm{m}^{3}\right)\end{array}$ & $\begin{array}{l}\text { Water } \\
(\mathrm{L})\end{array}$ & $\begin{array}{l}\text { Water } \\
\text { Cement } \\
\text { Ratio }\end{array}$ \\
\hline 360 & 1285 & 710 & 192 & 0.4 \\
\hline
\end{tabular}

\subsection{Testing And Specimen Details}

The specimens were designated as shown in Table 2. A total of 180 specimens were cast and tested to obtain the mechanical properties of NC, CSC and PFRCSC. The details of specimens cast for each mix are as follows.

(i) 18 cube specimens of $150 \mathrm{~mm}$ size to evaluate the unit weight, 28 day, 45 day and 60 day compressive strength

(ii) 6 cylindrical specimens of $150 \mathrm{~mm} \Phi$ and $300 \mathrm{~mm}$ height for the split tensile strength

(iii) 6 prisms of $100 \times 100 \times 500 \mathrm{~mm}$ for the modulus of rupture

Table 2 Designation of specimens

\begin{tabular}{|c|c|c|c|}
\hline Designation & Details & $\begin{array}{l}\text { Coconut } \\
\text { shell \% }\end{array}$ & $\begin{array}{l}\text { Volume } \\
\text { fraction } \\
\text { of PET } \\
\text { fibres }(\%)\end{array}$ \\
\hline $\mathrm{NC}$ & $\begin{array}{l}\text { Normal } \\
\text { Concrete }\end{array}$ & 0 & 0 \\
\hline CSC & $\begin{array}{l}\text { Coconut } \\
\text { Shell } \\
\text { Concrete }\end{array}$ & 10 & 0 \\
\hline PFRCSC1 & \multirow{4}{*}{$\begin{array}{l}\text { PET Fibre } \\
\text { Reinforced } \\
\text { CSC }\end{array}$} & \multirow{4}{*}{10} & 0.5 \\
\hline PFRCSC2 & & & 1.0 \\
\hline PFRCSC3 & & & 1.5 \\
\hline PFRCSC4 & & & 2.0 \\
\hline
\end{tabular}

\section{RESULTS \& DISCUSSIONS}

\subsection{Workability}

The concrete mixes with coconut shell aggregates were found to have better workability because of the smooth surface on one side of the coconut shells. The workability in terms of slump value was seen to follow an increasing trend with addition of coconut shells as well as PET fibres. The slump values increased by $6.2 \%$ between NC and CSC. The slump values gradually increased from 70 to $80 \mathrm{~mm}$ as the PET fibre volume fraction was increased from 0.5 to $2 \%$ as shown in Fig 3. For PFRCSC with $2 \%$ fibres, the increase in workability was $23 \%$ and $16 \%$ with respect to $\mathrm{NC}$ and CSC respectively.

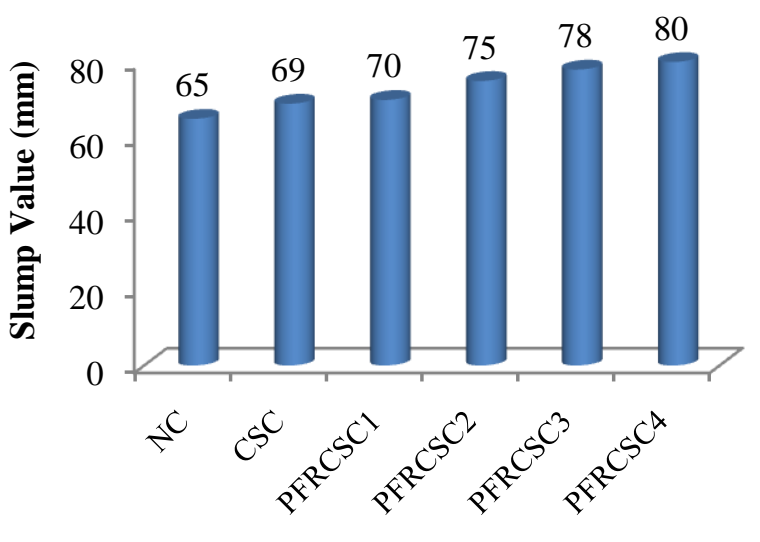

Designation of mix

Fig 3Slump values of mixes

The workability based on compaction factor was observed to increase from 0.91 to 0.924 as the percentage of PETfibres in CSC increased from 0 to $2 \%$ as shown in Fig 4. Increase in compaction factor between $\mathrm{NC}$ and CSCwas noted to be $1.11 \%$. For PFRCSC with $2 \%$ fibres, the increase was $2.7 \%$ and $1.6 \%$ with respect to $\mathrm{NC}$ and CSC respectively.

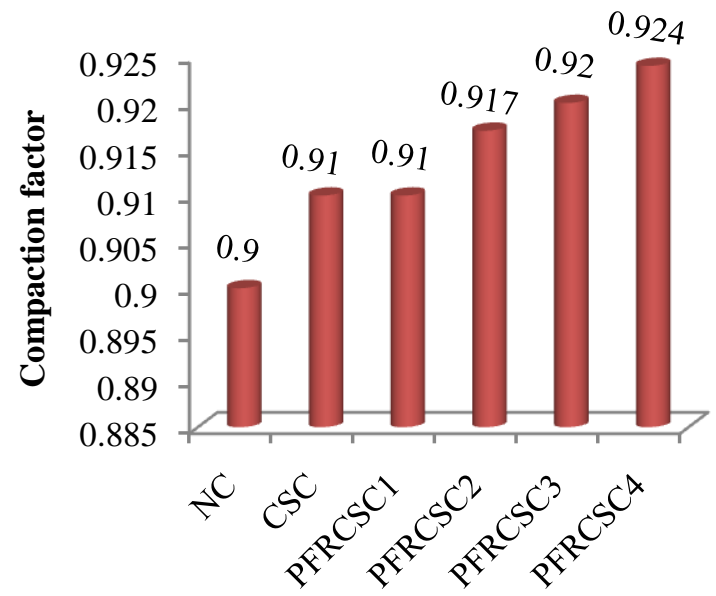

Designation of mixes

Fig 4Compaction factor values of mixes

\subsection{Density}

The densityof PFRCSC was seen to decrease with increase in fibre volume fraction. The maximum value of density for 
CSC was observed to be $2540.2 \mathrm{~kg} / \mathrm{m}^{3}$ as shown in Fig 5 . The density dropped down to $2056.3 \mathrm{~kg} / \mathrm{m}^{3}(20 \%)$ as volume fraction PET fibres in CSC was increased to $2 \%$. The decrease in density between NC and CSC was $2.8 \%$. It was also observed that the density values obtained for CSC and PFRCSC were lesser than the density of normal concrete, which usually ranges between 2300 to $2600 \mathrm{~kg} / \mathrm{m}^{3}$. Hence the concrete obtained by adding coconut shell and PET fibres could be categorised as light weight concrete.

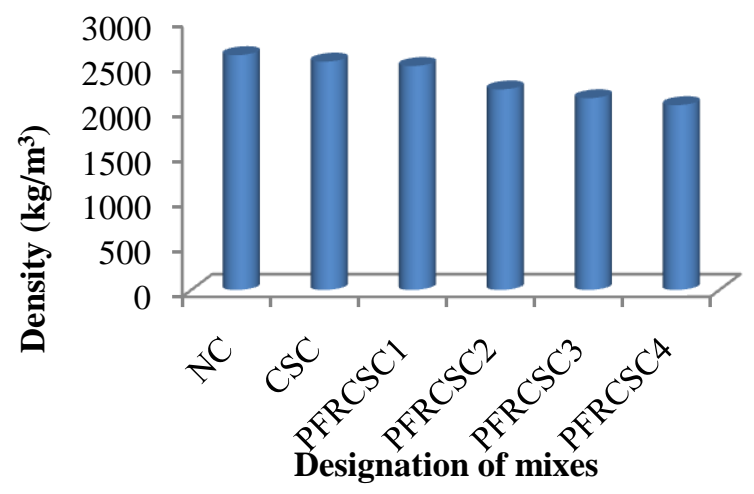

Fig 5Density

\subsection{Compressive Strength}

The compressive strength test was carried out on cube specimens with varying PET fibre contents.It has been observed that PFRCSC showed an increasing trend in the compressive strength with increase in PET content as shown in Fig6. The strength value at 28 days varied from 21.92 to $26.67 \mathrm{MPa}$ as the percentage fibres in CSC was increased from 0 to $2 \%$. As the age of the concrete increased beyond 28 days, it was seen that there was a gradual increase in strength till the end of 60 days. At the end of 60 days,all the specimens were having astrength $30.5 \mathrm{MPa}$. By increasing PET fibres in CSC from 0 to $2 \%$, the increase in strength was $21.7 \%, 36.5 \%$ and $37.3 \%$ at 28 days, 45 days and 60 days respectively.

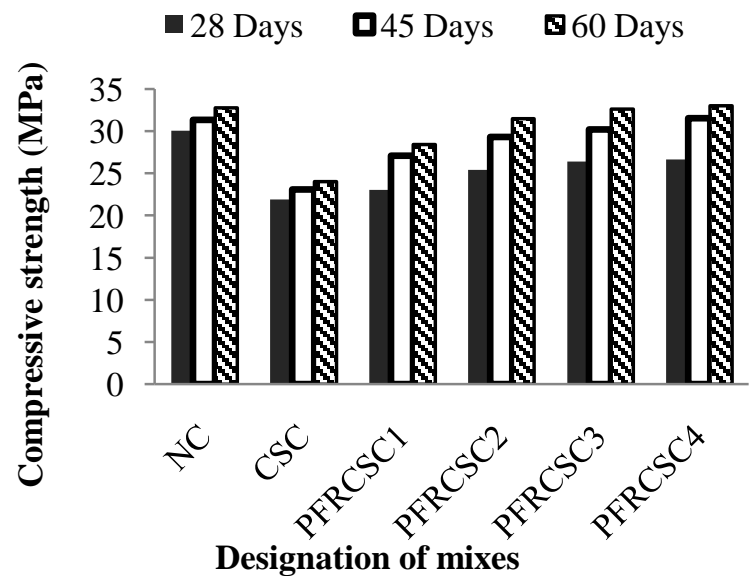

\subsection{Split Tensile Strength}

Fig 6Compressive strength

Split tensile strength test was carried out on cylindrical specimens horizontally placed between the loading surfaces of the compression testing machine. The load was applied until failure of the cylinder along the vertical diameter was observed.Split tensile strengthwas found to increase with increase in percentage of PET fibres as shown in Fig 7. The split tensile strength values increased to $1.85 \mathrm{MPa}$ as the fibre percentage was increasedfrom 0 to $2 \%$. The tensile strength of CSC increased by $1.7 \%$ when compared to $\mathrm{NC}$; while for PFRCSC with $2 \%$ fibres, the increase was $5.2 \%$ and $3.4 \%$ with respect to $\mathrm{NC}$ and $\mathrm{CSC}$ respectively.

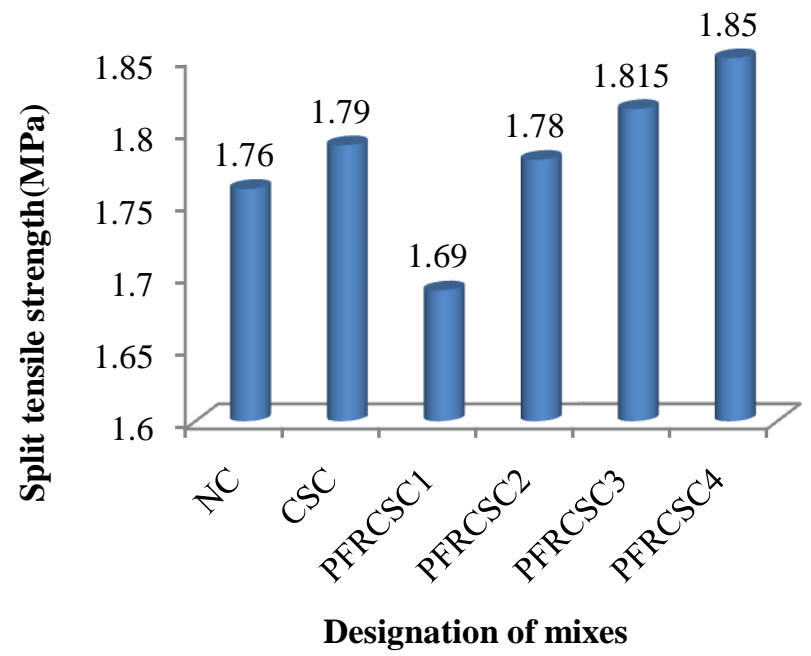

Fig 7 Split tensile strength

\subsection{Flexural Strength}

Flexural strength or the modulus of rupture (extreme fibre stress in bending) was found out by testing prisms under two-point loading.Flexural strengthwas observed to follow an increasing trendwith increase in percentage of PET fibres as shown in Fig 8. But, when compared to NC, the flexural strength values decreased from 5.6 to $4.8 \mathrm{MPa}$ as the fibre percentage was increased to $2 \%$. The decrease in flexural strengthof CSC when compared to NC was $42.8 \%$ while PFRCSC showed an improvement of $14.3 \%$ in the flexural strength with respect to CSC.

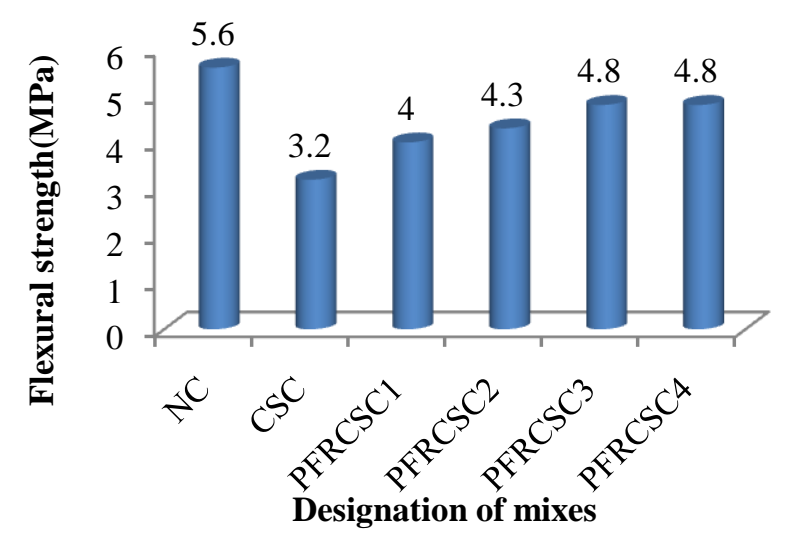

5. COST ANALYSIS

Fig 8 Flexural strength

According to the mix design,weight of coarse aggregate for one cubic meter is $1153.75 \mathrm{~kg}$ which costs Rs.1396. By the 
replacement of $10 \%$ of coarse aggregate with coconut shell, the weight of coarse aggregate obtained is $1038.375 \mathrm{~kg}$, which costs Rs.1256. This gives a reduction of Rs.140 for CSC when compared to normal concrete. The PET fibres and coconut shell are completely a waste material which does not cause any additional cost to the work. Hence, it was observed that around $25 \%$ cost reduction was obtained by using coconut shell and PET fibres in concrete and our project workwas economical.

\section{CONCLUSIONS}

An attempt has been made to effectively utilise waste materials like coconut shell and PET bottles in concrete as a solution to the huge disposal problems and environmental pollution hazards posed by these waste materials.Based on the above studies, the following conclusions are arrived at;

- $\quad$ CSC and PFRCSC are concretes which promote green construction.

- Coconut shell and PET fibres are compatible with the cement in concrete and improves the workability of the concrete mix.

- PFRCSC exhibits improvement in compressive strength, flexural strength and split tensile strength in comparison to conventional concrete and coconut shell concrete.

- $\quad$ PFRCSC can be categorised as light weight concrete.

- PFRCSC also contributes to the reduction of coarse aggregate usage in concretes, thereby reducing the production cost and depletion of natural resources.

Hence it can be concluded that PFRCSC is a low cost, light weight and an eco-friendly concrete with improved strength characteristics.

\section{REFERENCES}

[1]. Akshay, S S, Kalyani, R N, Pooja, P K, Shraddha, P G.,(2014) Coconut shell as partial replacement for coarse aggregate: Review, International Journal of civil engineering research , 5(3), 211-214.

[2]. Amarnath, Y, and Ramachandrudu, C.,(2012) Properties of concrete with coconut shells as aggregate replacement, International Journal of engineering Inventions, 1(6), 21-31.

[3]. Anjali, S K, Priyanka, A B, Shashiraj, S C.,(2015)Investigation of coconut shell as a replacement of coarse aggregate in concrete, Journal of information, knowledge and research in civil engineering, 3(2), 195-198.

[4]. Daniel,Y.,(2013) Experimental assessment on coconut shells as aggregate in concrete, International Journal of engineering science inventions, 2(5), 7-11.

[5]. Dewanshu, A. and Kalurkar, L G.,(2014), Coconut shell as partial replacement of coarse aggregate in concrete, IOSR Journal of Mechanical and Civil engineering, International Conference on Advances in Engineering and Technology,61-64.

[6]. Ganesh P, Arunkumar C, Pandiyaraj R, Rajesh P, Sasikumar L (2014) Study on utilisation of waste PET bottle fiber in concrete, International Journal of
Research in Engineering and Technology 2(5),233240.

[7]. Gopal, C. and Ranjan, K.,(2013), Effect of coconut shell aggregate on normal strength concrete, International Journal of engineering research and technology, 2(6), 2405-2415.

[8]. Irwan J M, Asyraf R M, Othman N, Koh H B, Annas M M K, Fisal S K.,(2013) The mechanical properties of PET fiber reinforced concrete fromrecycled bottle wastes, Advanced Materials Research,795, 347-351.

[9]. Kandasamy R., and Murugesan R., (2011), Fibre reinforced concrete using domestic waste plastics as fibres,ARPN Journal of Engineering and Applied Sciences,6(3),75-82.

[10]. Maninder, K, Manpreet, K.,(2012), A Review on utilisation of coconut shell as coarse aggregates in mass concrete, International journal of applied engineering research, 7(11).

[11]. Nibudey R N, Nagarnaik P B, Parbat D K, Pande A K.,(2013)Strength and fracture properties of post consumed waste plastic Fiber reinforced concrete, International Journal of Civil, Structural, Environmental and Infrastructure Engineering, $3(2), 9-16$.

[12]. Rajeevan, B.,(2015) A study on the utilisation of coconut shell as coarse aggregate in concrete, International Journal of engineering research and technology, 4(7), 77-80.

[13]. Sreenivasulu, D, Praveen, K, Satish, K, Sri Harsha, $\mathrm{K}$, Mahesh, V.,(2014) Laboratory investigation on coconut shell in concrete: An alternative low cost building, Journal of chemical and pharmaceutical sciences, 4, 41-43.

[14]. Suganya, Aastha T M, Swaptik C.,(2013)Polyethylene terephthalate waste as building solution International Journal of Chemical and Biological Sciences, 1(2).

[15]. IS 12269: 1987 (reaffirmed 2004): Specifications for 53 Grade ordinary Portland cement, Bureau of Indian Standards, New Delhi, P.5

[16]. IS 383: 1970 (reaffirmed 2002): Specification for coarse and fine aggregates from natural sources for concrete, Bureau of Indian Standards, New Delhi, P.19

[17]. IS 2386 (Part I): 1963 (reaffirmed 2002): Methods of Test for Aggregates for Concrete, Bureau of Indian Standards, New Delhi, P.17.

[18]. IS 2386 (Part III): 1963 (reaffirmed 2002): Methods of test for aggregates for concrete Part 3 - Specific gravity, density, voids, absorption and bulking, Bureau of Indian Standards, New Delhi, P.17. 